\title{
Leucopenia, Neutropenia, Lymphopenia and Monocytopenia in a 15 year Old Girl with Iron Deficiency Anemia Responding to Iron Therapy: A Case Report
}

\author{
Sam Hassan*, Tessy Augustine, Nidal Mahgoub \\ Department of Pediatrics, Mediclinic City Hospital, Dubai, United Arab Emirates \\ Email address: \\ samhassan@mediclic.ae (S. Hassan), tessy.augustine@mediclinic.ae (T. Augustine), nidal.mahgoub@mediclinic.ae (N. Mahgoub) \\ ${ }^{*}$ Corresponding author
}

To cite this article:

Sam Hassan, Tessy Augustine, Nidal Mahgoub. Leucopenia, Neutropenia, Lymphopenia and Monocytopenia in a 15 year Old Girl with Iron Deficiency Anemia Responding to Iron Therapy: A Case Report. American Journal of Pediatrics. Vol. 6, No. 3, 2020, pp. $322-326$. doi: 10.11648/j.ajp.20200603.35

Received: July 8, 2020; Accepted: July 27, 2020; Published: August 18, 2020

\begin{abstract}
Despite the high prevalence of iron deficiency anemia (IDA) in children, extensive information about its impact on growth and cognitive functions, less is known about how it affects the non-erythrocytes cell lines and its implications. High erythropoietin levels in severe iron deficiency anemia may down regulate the production of non- erythroid precursors resulting in various cytopenia, however, the mechanism of this is not fully understood. Reports depicting the association of iron deficiency anemia with cytopenia is quite scarce in pediatric population. We report a case of a 15 year old girl presented with severe iron deficiency anemia and leucopenia, lymphopenia, neutropenia and monocytopenia who has no other evidence of bone marrow dysfunction. The patient responded to iron therapy with prompt reversal of all cell counts. It is therefore recommended to include iron study and plasma erythropoietin concentration in the evaluation of otherwise healthy children presenting with cytopenia. Likewise, to consider iron deficiency in the causative list of non-erythroid cytopenia such as neutropenia.
\end{abstract}

Keywords: Iron Deficiency Anemia, Erythropoietin, Leucopenia, Neutropenia, Monocytopenai, Lymphopenia

\section{Introduction}

Iron deficiency anaemia is the most common global nutritional deficiency and significant public health problem especially in the developing countries. There are about 500600 million people having IDA with prevalence more in children and pregnant women. Iron is an important factor in children for neurodevelopment, immune system, cognitive abilities, growth and Quality of Life aspects. Many studies showed that iron regulates the functions of lymphocytes and the cell mediated immunity, hence ferritin usually increases in acute infections [1]. Despite these important functions its mechanism is not well elucidated. There are very scarce reports about the effects of IDA on the counts of nonerythroid blood cells and the mechanism of this effect is yet to be clarified.
It is well known that Iron deficiency with or without anemia is associated with increased susceptibility to infection owing to impaired immune function. IDA is usually accompanied by normal leucocyte count and normal or elevated platelets. The risk of infections increased more when the IDA is associated with reduction in the numbers of leucocytes, neutrophils and other immunogenic cells. We report a case of IDA due to nutritional and recurrent menorrhagia in a healthy child with neutropenia, leucopenia, lymphopenia and monocytopenia. All cell counts and the hemoglobin improved to the iron replacement therapy. This case report highlights the importance of iron as a cause for neutropenia, leucopenia and other cytopenia. The mechanism is not clear yet but likely to be multiple which will be discussed here. 


\section{Case Report}

Fifteen year old girl presented with dizziness, tiredness and feeling fast heart rate for more than 1 month. Her parents noted that she has pale skin and mucus membrane for last few days. She was a previously healthy child who attained menarche 2 years ago. However she has moderate menorrhagia lasting for 7 to 10 days each cycle. She is one among the twins and has three other siblings. Two of her sisters had polycystic ovaries, one of them had ovariectomy and suffered from iron deficiency anaemia (IDA) requiring intravenous iron infusion. Apart from her maternal cousin being a career of thalassemia, there is no significant haematological or autoimmune diseases in the family. Though there are no food intolerance or allergies, she is a vegetarian by choice. Physical examination was uneventful apart from pallor in skin and mucus membranes and a soft ejection systolic murmur of grade $2 / 6$ at the left sternal edge. Her temperature was $37.3^{\circ} \mathrm{C}$, respiratory rate 18 per minute, blood pressure $115 / 66$, heart rate 125 per minutes, and $\mathrm{SaO}_{2}$ $100 \%$ in room air.

Initial blood counts prior to admission showed a haemoglobin $(\mathrm{Hb})$ of $5.1 \mathrm{~g} \%$, white cell count (WCC) of 2 $\mathrm{K} / \mathrm{ul}$, red blood cells $(\mathrm{RBC}) 2.97 \mathrm{M} / \mathrm{ul}$ and an absolute neutrophil $(\mathrm{N})$ count of 0.8 . The patient was admitted for investigation of anaemia, leucopoenia and neutropenia. The lymphocytes and monocytes were low too (Table 1).

On admission her blood counts decreased father with $\mathrm{Hb}$ of $4.6 \mathrm{~g} \%$, WCC of $1.9 \mathrm{~K} / \mathrm{ul}, \mathrm{RBC} 2.7 \mathrm{M} / \mathrm{ul}, \mathrm{N} 0.8$ and the rest of her blood counts as in (Table 1) that showed normal platelets and reticulocyte counts. Chest x-ray and echocardiography were unremarkable. Abdominal ultrasound showed bilateral tiny ovarian follicles that was reviewed by gynaecologist as normal. The plasma concentrations of androstenedione and oestrogens were normal. After investigations (Table 1) a diagnosis of IDA due to dietary intake and aggravated by moderate menorrhagia was made. However, the patient also presented with neutropenia, leukopenia, lymphopenia and monocytopenia. As far as our search in English literature was concerned we have come across only a single case report of iron deficiency anemia with pancytopenia in a 7 year old boy [2]. However it was not clear whether serum copper, erythropoietin (EPO) and viral screens were known in that case report. Moreover the mechanism by which the iron deficiency leading to pancytopenia is not yet elucidated. In our case the serum level of EPO was high $967 \mathrm{UI} / \mathrm{L}$ (normal range 4.2-27.8) and this will be discussed as a possible cause for the pancytopenia. The serum copper concentration was normal $108 \mu \mathrm{g} / \mathrm{dl}$ (normal range 64-117).

The patient was started on intravenous infusions of ferric Carboxymaltose, $250 \mathrm{mg}, 2$ times per week for a total of 8 doses and vitamin D of 50,000 IU/ week for 8 weeks as the level of vitamin D was very low $7.4 \mathrm{ng} / \mathrm{L}$ only. The repeated blood tests showed improvement of $\mathrm{Hb}, \mathrm{WCC}, \mathrm{N}, \mathrm{L}$ and monocytes following the first infusion and then subsequently as in (Table 2).
Table 1. Blood results before iron therapy.

\begin{tabular}{|c|c|}
\hline White cell count (K/ul) & 1.9 \\
\hline Red blood cell count (M/ul) & 2.72 \\
\hline Haemoglobin (g/dl) & 4.6 \\
\hline MCV (fl) & 67.3 \\
\hline MCH (pg) & 16.9 \\
\hline $\operatorname{MCHC}(\mathrm{g} / \mathrm{dl})$ & 25.1 \\
\hline RDW (\%) & 16.7 \\
\hline Platelet count (K/ul) & 210 \\
\hline Neutrophils (K/ul) & 0.88 \\
\hline Lymphocytes (K/ul) & 0.84 \\
\hline Monocytes (K/ul) & 0.15 \\
\hline Ferritin (ng/ml) & 0.1 \\
\hline Iron (umol/L) & $<2.1$ \\
\hline $\mathrm{EPO}(\mathrm{UI} / \mathrm{L})$ & $967(4.2-27.8)$ \\
\hline TIBC (umol/L) & 95.2 \\
\hline Transferrin (mg/dl) & 381 \\
\hline Coombs test & Negative \\
\hline Peripheral smear & $\begin{array}{l}\text { Microcytic anemia suggestive of iron } \\
\text { deficiency }\end{array}$ \\
\hline Reticulocyte count (\%) & 1.63 \\
\hline LDH (U/L) & 178 \\
\hline Vitamin B12 (pmol/L) & 179 \\
\hline Folate $(\mathrm{ng} / \mathrm{mL})$ & 8.8 \\
\hline Vitamin D (ng/L) & 7.4 \\
\hline Antinuclear antibody profile & Negative \\
\hline Coeliac screen & Negative \\
\hline Stool occult blood & Negative \\
\hline Haemoglobin electrophoresis & Decreased $\mathrm{HbA} 2(1.7 \%)$ \\
\hline Lead & Not detected \\
\hline Copper & $108 \mu \mathrm{g} / \mathrm{dl}(64-117)$ \\
\hline
\end{tabular}

Table 2. Blood results post iron infusion (arrows indicates repeated results).

\begin{tabular}{ll}
\hline White cell count $(\mathbf{K} / \mathbf{u l})$ & $\mathbf{3 . 5} \rightarrow \mathbf{3} \rightarrow \mathbf{3 . 4}$ \\
\hline Red blood cell count $(\mathrm{M} / \mathrm{ul})$ & $2.98 \rightarrow 3.07 \rightarrow 3.73$ \\
Haemoglobin $(\mathrm{g} / \mathrm{dl})$ & $5.2 \rightarrow 6.4 \rightarrow 9.3$ \\
Neutrophils $(\mathrm{K} / \mathrm{ul})$ & $1.8 \rightarrow 2.2 \rightarrow 1.2$ \\
Lymphocytes $(\mathrm{K} / \mathrm{ul})$ & $1.4 \rightarrow 1.4 \rightarrow 1.7$ \\
Monocytes $(\mathrm{K} / \mathrm{ul})$ & $0.2 \rightarrow 0.2 \rightarrow 0.3$ \\
\hline
\end{tabular}

\section{Discussion}

This is an otherwise healthy 15 year old girl who suffered from recurrent viral and throat infections. She presented with a history, clinical examination and blood tests suggestive of severe IDA due to nutritional cause and menorrhagia. Her blood tests in addition to low $\mathrm{RBC}$ and $\mathrm{Hb}$ showed reduction in neutrophils, leucocytes, lymphocytes and monocytes which were corrected after iron therapy. Although we know that iron plays important role in the cellular immune functions, the mechanism of this is not well known. It has been reported that iron plays an important role in the immune function of neutrophils [3, 4], however there are scarce reports about its role on the counts of neutrophils and other non-erythroid cells.

Leukopenia and significant lymphopenia were identified in patients with IDA [5] and the severity correlate with $\mathrm{Hb}$ in a dose-dependent manner [6]. Nevertheless not all studies found such association in healthy children [7]. Moreover the mechanism of this rare association in a common disease is not yet clear if it is due to the iron deficiency or EPO or both. Shunting effect of EPO on cell production and receptor 
effects were speculated [8]. However iron dependent enzymes in production of non-erythroid cells might be the cause [9].

Studies have been shown that in IDA, the enzyme EPO produced by the interstitial fibroblast in the kidney increased in a stepwise manner in response to the resultant hypoxemia as the serum iron level and $\mathrm{Hb}$ decreased. In foetal and neonatal period, EPO produced by the liver mainly but it is also produced by brain, astrocytes and neurons and attain tissue protective effect such as in the brain [10]. It acts mainly on bone marrow on the precursors of the red blood cells to increase the production of RBCs. It also protects these precursors from apoptosis hence promote their survival. The mechanism of action of EPO is expressed by EPO receptors in the precursor cells. EPO receptors were also found in heart, muscles, kidney and central nervous tissues. EPO level is quite low in the absence of IDA of not more than $10 \mathrm{mU} / \mathrm{mL}$ but increased up to 1000 fold in hypoxemia with a negative feedback related to the serum iron concentrations [11]. EPO mainly acts on erythroid progenitor cells in bone marrow. Its effect on non-erythroid cells such as neutrophils and white cells counts have not been clarified. Some studies suggest no effects while others support reduction or even toxic effects $[12,13]$. In IDA there is an increase in the concentration of serum EPO however it is not clear at what point of iron or hemoglobin concentrations this increment starts to happen, neither at what point of concentrations, it may switch off the counts of other cells in favor of erythroid production. In our patient, the IDA was associated with reduction of the counts of other cells. The EPO was high in this patient. It has been found that EPO inhibit the formation of granulocytes in favor of erythrocytes formation [14] in a stepwise reduction of $\mathrm{N}$ when the dose of EPO increased [15]. However not all studies support granulocytes suppression when EPO injections used [16] particularly in low doses [17]. It seems that reduction in $\mathrm{N}$ and WCC happen only in chronic anemia when the EPO reached a higher concentration. This suggests that there is a shifting point in the iron concentration for a specific period of time after which the EPO primed a process to suppress the formation of non-erythrocytes shifting the pluripotential cells toward the production of RBC. When the iron is corrected that set point is over taken and hence the improvement of the whole cell counts. More studies are needed in vivo and in vitro to elucidate this possible phenomenon of both the iron and the EPO interaction effect on bone marrow progenitors. In our patient when the iron treatment started, it corrected not only the $\mathrm{Hb}$, serum ferritin and iron but also the other nonerythroid cells namely the neutrophils, white cell counts, lymphocytes and monocytes. This indicates that patients treated with high doses of EPO should have their white cell and differential counts monitored closely. On the other hand patients presented with neutropenia and leucopoenia should have their iron status and EPO checked. Idiopathic chronic neutropenia and or leucopoenia due to IDA might be missed and the patients might be extensively investigated if the iron deficiency is not considered in the causes [18]. However the cause of that association needs further elucidations and studies.

In our patient the EPO was high, which might have down regulated the production of neutrophil [19]. This may be true for the down regulation of the total white cells too. Clinicians should be aware that iron treatment may lead to worsening of this down regulation phenomena temporarily due to stem cell steal phenomena. When the iron becomes available to the pluripotent stem cells, it favours the production of the RBC temporarily, possibly due to the effect of erythropoietin which prioritize the activation of the RBC production [20].

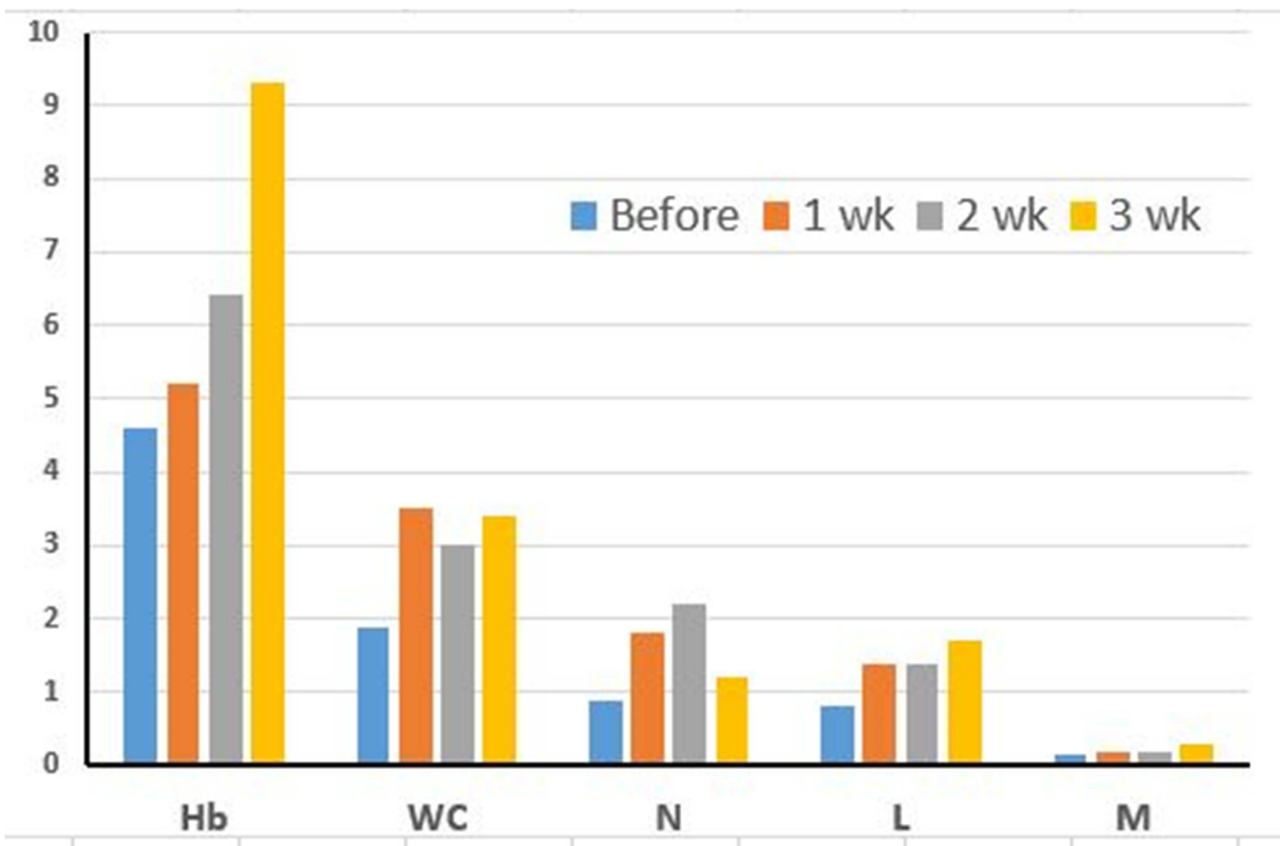

Figure 1. Serum level and counts of haemoglobin (Hb), White cells (WC), neutrophils (N), lymphocytes (L) and monocytes (M) before and in weeks (wk) 1, 2, and 3 after IV infusion of iron. 
In figure 1 , are the level of $\mathrm{Hb}$ in blood and the counts of other cells before and after intravenous infusion of iron. It is clear that the basal values before treatment for the cell counts and $\mathrm{Hb}$ are low. The level of $\mathrm{Hb}$ then increased steadily after the IV infusion of iron as do the cell counts in the first week of treatment ( 3 infusion given). Interestingly when the $\mathrm{Hb}$ increased above 6.5 in week 3 of treatment the $\mathrm{N}$ counts dropped down which might be explained by the steal off phenomena in favour of the $\mathrm{Hb}$ increased production. When the $\mathrm{Hb}$ production doubled at week 3 the $\mathrm{N}$ started to drop down. That steal phenomena may reach a plateau then the cell production balanced towards all. Unfortunately, we do not have the level of EPO to compare its effect as and when it decreased. Studies are needed in this aspect.

Children with copper deficiency might present with IDA and pancytopenia association but still due to unclear aetiology [21]. However in our patient copper deficiency is very unlikely since the WCC, N, L, M and RBC, iron were all corrected back to normal with iron treatment only and there were no clinical features of copper deficiency and her serum copper was normal.

The role of vitamin D as an immune-modulator and in the innate immune system and autoimmunity were studied extensively recently. Our patient showed very low vitamin D level $(7.4 \mathrm{ng} / \mathrm{ml})$, however it is very unlikely that it contributed to the low blood cells counts. Some studies showed a link between low vitamin D and increased eosinophil count and allergic diseases such as atopy and asthma but that was not the case here. One can suggest that both vitamin D deficiency and IDA can happen in the same patient and should be investigated reciprocally in cases of nutritional causes of either. Vitamin D deficiency may be partially linked to IDA [22] hence it is recommended to check vitamin D level in IDA.

\section{Conclusion}

This case report demonstrates the association of cytopenia in severe iron deficiency anemia possibly due to high erythropoietin which down regulates the non erythroid progenitor cells. It emphasises the importance of checking iron and EPO levels in otherwise healthy children presenting with cytopenia before extensive investigations, as iron therapy could reverse the cell counts.

\section{Authors' Contributions}

The authors contributed equally to the article.

\section{Disclosure Policy}

The authors declare that there is no conflict of interest regarding the publication of this paper.

\section{Acknowledgements}

Thanks to go to the parents of the child and all of those who contributed to the management.

\section{References}

[1] Aly, S. S., Fayed, H. M., Ismail, A. M. et al. Assessment of peripheral blood lymphocyte subsets in children with iron deficiency anemia. BMC Pediatr 18, 49 (2018). https://doi.org/10.1186/s12887-018-0990-5.

[2] Haloom Abdel Salam Elhashmi; pancytopenia in 7year old child with severe iron deficiency anemia; International journal of science and research (IJSR): Volume 8, issue 10, October 2019.

[3] Cronin SJF, Woolf CJ, Weiss G et al, The role of iron regulation in immunometabolism and immune-related disease; $\begin{array}{llll}\text { Front. } & \text { Mol. } & \text { Biosci, }\end{array}$ https://doi.org/10.3389/fmolb.2019.00116.

[4] Lehman HK, Segal BH; The role of neutrophils in host defense and disease; J Allergy and Clin Immunol; 2020; 145: 1535-1544; https://doi.org/10.1016/j.jaci.2020.02.038.

[5] Lim Y, Lee E, Choi I et al; Leukopenia in Patients with Iron Deficiency Anemia. (2011); Blood. 118. 5279-5279. 10.1182/blood. V118.21.5279.5279.

[6] Yoojoo Lim, Eun Young Lee, In Sil Choi, Tae-Yong Kim, Sung-Soo Yoon, Ki Hwan Kim; Leukopenia in Patients with Iron Deficiency Anemia. Blood 2011; 118 (21): 5279. doi: https://doi.org/10.1182/blood.V118.21.5279.5279).

[7] Onabanjo O, Jerling J C, Covic $\mathrm{N}$ et al; Association between iron status and white blood cell counts in African school children of the North-West Province, South Africa Author links open overlay panel; (2012) J Epidemiol and Global Health; 2: 103-110 https://doi.org/10.1016/j.jegh.2012.07.003.

[8] McDonald TP, Clift RE, Cottrell MB. Large, chronic doses of erythropoietin cause thrombocytopenia in mice. Blood 1992, 80: $352-8$

[9] Abbaspour N, Hurrell R, Kelishadi R. Review on iron and its importance for human health. J Res Med Sci. 2014; 19 (2): 164-174.

[10] Teramo, K. A., Klemetti, M. M. \& Widness, J. A. Robust increases in erythropoietin production by the hypoxic fetus is a response to protect the brain and other vital organs. Pediatr Res 84, 807-812 (2018). https://doi.org/10.1038/s41390-0180054-4.

[11] Tojo Y, Sekine H, Hirano I et al; Hypoxia Signaling Cascade for Erythropoietin Production in Hepatocytes; (2015); Molecular and Cellular Biology; 35 (15) 2658-2672; DOI: 10.1128/MCB.00161-15; DOI: 10.1128/MCB.00161-15.

[12] Wright D, Wright E C, Noguchi C T; Neutropenia in Myelosuppressed Cancer Patients Treated with Recombinant Human Erythropoietin (EPO). Blood 2019; 134 (Supplement_1): 1034. doi: https://doi.org/10.1182/blood2019-126650.

[13] Avneon M, Lifshitz L, Katz O et al, (2009). Non-erythroid effects of erythropoietin: Are neutrophils a target? Leukemia research; 33: 1430-1432. 10.1016/j.leukres.2009.03.020.). 
[14] Cantarelli, C, Angeletti, A, Cravedi, P. Erythropoietin, a multifaceted protein with innate and adaptive immune modulatory activity. Am J Transplant. 2019; 19: 2407-2414 https://doi.org/10.1111/ajt.15369.

[15] Suresh S, Rajvanshi PK, Noguchi CT, The Many Facets of Erythropoietin Physiologic and Metabolic Response; (2020); Front. $\quad$ Physiol., 17 January 2020; https://doi.org/10.3389/fphys.2019.01534.

[16] 003 1-3998/90/2706-0583\$02.00/0 PEDIATRIC RESEARCH Copyright 01990 International Pediatric Research Foundation, Inc Vol. 27, No. 6, 1990 Printed in (I. S. A Effect of Erythropoietin on Granulocytopoiesis: In Vitro and in Vivo Studies in Weanling Rats JOYCE M. KOENIG AND ROBERT D. CHRISTENSEN Division of Human Development and Aging, University of Utah School of Medicine, Salt Lake City, Utah 84132.

[17] Stone WJ, Graber SE, Krants SB, et al; Treatment of the anemia of predialysis patients with recombinant human erythropoietin: a randomized, placebo-controlled trial. Am J Med Sci; 1988; 296: 171-179.
[18] Abuirmeileh, A., Bahnassi, A. \& Abuirmeileh, A. Unexplained chronic leukopenia treated with oral iron supplements. Int J Clin Pharm; 201436, 264-267. https://doi.org/10.1007/s11096-013-9897-2.

[19] Christensen RD, Liechty KW, Koenig JM, et al. Administration of erythropoietin to newborn rats results in diminished neutrophil production. Blood. 1991; 78: 12411246).

[20] Ganti AK, Shonka NA, Haire WD. Pancytopenia due to iron deficiency worsened by iron infusion: a case report. J Med Case Rep. 2007; 1: 175. doi: 10.1186/1752-1947-1-175.

[21] Harless W, Crowell E, Abraham J. Anemia and neutropenia associated with copper deficiency of unclear etiology. Am J Hematol. 2006; 81 (7): 546-549. doi: 10.1002/ajh. 20647.

[22] Soliman AT, Eldabbagh M, and Elawwa A. Does Vitamin D therapy affect hematological indices in adolescents with vitamin D deficiency?. Indian J Endocrinol Metab. 2012; 16 (4): 659-660. doi: 10.4103/2230-8210.98038. 